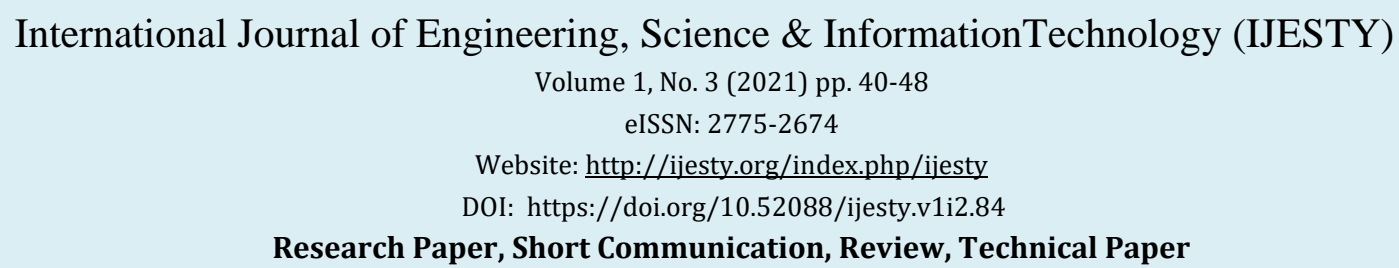

\title{
Artificial Neural Network Model For Wind Mill
}

\author{
Zulfian Azmi \\ Department of Information System, STMIK Triguna Dharma, Medan, Indonesia \\ *Corresponding author E-mail: zulfian azmi@gmail.com
}

Manuscript received 15 April 2021; revised 1 May 2021; accepted 15 June 2021. Date of publication 3 July 2021

\begin{abstract}
Utilization of wind energy sources provides advantages in terms of being environmentally friendly, and it can be energy source is realible. The analysis of wind mill control using Neural Network model for Uncertain Variables or abbreviated as the VTP model is expected to provide a solution in solving the windmill control case. And the Neural Network model for Uncertain Variables uses probability techniques, degree of membership, logical OR function, linear programming and euclidean distance to reduce the learning process In this research, wind mill control uses variable air pressure and duration of sunshine to determine whether the wind mill is moving or not. Finally, this research tries to analyze windmill control, which in the future is expected to produce a smart wind mill control system. And the Neural Network model for Uncertain Variables can be used to control windmills with the different of input data.
\end{abstract}

Keywords: Control, Wind mill, ANN, Uncertain Variable, Air Pressure.

\section{Introduction}

The increasing demand for energy globally along with the emission of harmful gases caused by conventional fossil fuel sources, such as coal and oil, the search for new clean and renewable energy has become an important issue for the development of human society. It has made the need to increase the use of renewable energy sources very important. Therefore, the development of renewable energy is a common trend in today's world. [1]. Fossil energy sources that have been used so far are estimated to be exhausted, due to massive exploitation to offset the need for energy for needs. For this reason, it is necessary to develop renewable sources of electrical energy, natural energy sources that can be used freely, without being limited. One of them is wind energy. Utilization of wind energy sources provides advantages in terms of being environmentally friendly, does not cause pollution that can damage the environment. And wind power can be a reliable source of energy, exploitable to meet both the global demand for renewable energy directly. According to the European energy roadmap 2050[2], the share of renewable energy increases substantially across all scenarios, reaching at least $55 \%$ in the final gross energy consumption by 2050 , an increase of 45 percentage points from the current level of around $10 \%$. Wind power is a renewable energy source used primarily for the production of electricity. Global wind resources (onshore and nearshore) are estimated at 72 TW which is seven times the world's electricity demand and five times the world's energy demand.

Currently, renewable energy is needed, because the need for electrical energy in Indonesia is increasing every year. Energy needs are increasing gradually, both in terms of capacity, quality and distribution demands. The increasing demand for electrical energy in Indonesia every year is in line with the increase in national economic growth. Because it is so large, then this will be a problem if the supply is not in line with the needs. To overcome this electricity demand, a new energy source is needed that is able to meet the growing national electricity demand. Wind as an alternative energy source that is widely available in nature can be used as a source of electrical energy. Wind is an inexhaustible source of energy so that the use of this energy as an energy source will have a positive impact on national electricity needs.

The factor that determines the movement of the wind is due to the difference in pressure in nature. Airflow flows through the pressure over a large area to a small area. The flow of air that blows in nature is a result of the difference in wind temperature gain. So that the difference in temperature causes a difference in pressure, and produces wind flow. As according to a meteorologist, from the Netherlands Buy Bollots, which can be concluded that the wind flows from an area that has a large area of pressure to a small area. The flowing wind will blow in the entire area of the natural area, so the area has the ability to function the power of air flow. Usually the flat area is more useful than the area of the earth's surface and other shapes. And the wind is formed from differences in air pressure due to the uneven heating of the earth's surface by the sun. Some areas that have a lot of air speed, such as coastal areas or seaside, deserts and others. In addition, areas that can increase the speed of moving air, for example at the top of a hill or in the gap between mountains. The movement of all the suns every three months causes a shift in the location of the heating of the earth's surface. The impact of this phenomenon causes differences in air pressure in the Northern Hemisphere (BBU) and Southern Hemisphere (BBS). Wind potential that can be used for wind energy generation is wind potential with a minimum speed of $4.36 \mathrm{~m} / \mathrm{s}$. And in certain cases in Indonesia, the number of electric

Copyright $(\mathcal{C}$ Authors. This is an open access article distributed under the Creative Commons Attribution License, which permits unrestricted use, distribution, and reproduction in any medium, provided the original work is properly cited. 
generators comes from air power that moves at an average moving air speed of $2.5 \mathrm{~m} / \mathrm{s}$ equals $9 \mathrm{~km} / \mathrm{hour}$ or $5.0 \mathrm{knots} / \mathrm{hour}$ according to support plantation activities or human activities related to management and utilization of aquatic biological resources. For example for irrigation needs of ponds and others.

As of April 2013, the London Array is the largest offshore wind farm in the world with a current capacity of 630 MW, and the Gansu Wind Farm is the world's largest onshore wind farm, with a current capacity of 5160 MW and will reach 20000 MW by 2020 [2]. Furthermore, the development of wind farms around the world is spreading rapidly and wind energy has become an important factor for promoting sustainable development. But negative consequences like accidents, environmental effects and others are highlighted. Especially the visual impact on the landscape and noise pollution are some of the factors that provoke social reactions. In addition to the allowable wind flow process and the length of power generation, the high capital cost of investment and network instability due to the intermittent nature of the wind, are also significant obstacles in the development of wind energy production[3].

Historically, the first windmill used to generate electricity was built by P. La Cour from Denmark at the end of the 19th century. After World War I, a sail with a cross section resembling an airplane propeller angle is now called a propeller type windmill or turbine. The twin angle windmill experiment was carried out in the United States in 1940, the size of which was very large called the Smith-Putman engine, because it was designed by Palmer Putman, the capacity of $1.25 \mathrm{MW}$ made by the Morgen Smith Company of York Pensylvania [4]. This wind turbine was originally created to accommodate the needs of farmers in doing rice milling, for irrigation purposes, etc. Many early wind turbines were built in Denmark, the Netherlands, and other European countries. Now more wind turbines are used to accommodate people's electricity needs, using the principle of energy conversion and using renewable natural resources, namely wind. Although until now the construction of wind turbines has not been able to compete with conventional power plants such as PLTD, PLTU and so on. So it is deemed very necessary to know more about wind energy and wind power generation.

The speed of the blowing wind is influenced by several factors, including the barometric gradient (the difference in air pressure between two isobars at each straight distance of 15 meridians or $111 \mathrm{~km}$ ). Barometric gradient, location of place, height of place and time of Dan as formulated in Stevenson's law. According to Stevenson, the strength of the wind blowing is directly proportional to its barometric gradient. The greater the barometric gradient, the stronger the wind is blowing. The barometric gradient is the difference in air pressure between two isobars at any straight distance of 15 meridians or $111 \mathrm{~km} \mathrm{[5].} \mathrm{A} \mathrm{wind} \mathrm{turbine} \mathrm{is} \mathrm{a} \mathrm{device} \mathrm{used} \mathrm{to} \mathrm{convert} \mathrm{the} \mathrm{kinetic} \mathrm{energy}$ stored in the wind into electrical energy. While windmills are equipment used to convert wind energy into mechanical power. The development of wind turbines has made significant progress since the late 1960s. Several studies were conducted at home and abroad to make wind turbines with a diameter of $2 \mathrm{~cm}$ and an outer diameter of $3.2 \mathrm{~cm} \mathrm{[6].}$

Utilization of artificial intelligence is an important thing whose performance is to adopt the expertise of an expert and store his knowledge in a computer that is able to solve uncertainties [7]. Then the use of Artificial Neural Networks which is an information processing with a learning process, by conducting training and testing [8]. Neural Networks have processing capabilities and the ability to learn from examples so that Artificial Neural Networks become an efficient problem solving paradigm. Artificial Neural Networks which have characteristics similar to biological neural networks. This network as assuming that, information occurs and is transmitted between neurons. Neurons have weights that will amplify the signal. and to determine the input, each neuron uses the activation function to be imposed on the number of inputs received and then compared with the threshold [9]. Artificial Neural Networks can be implemented in various applications such as pattern recognition, weather, prediction, handwriting recognition, facial recognition, autopilot, robotics, predicting the weather for solar and wind radiation [10]. And the application of the neural network model has not yet provided optimal results in learning with non-binary, uncertain and variable input values. The input variable is not only 1 and 0 but allows between 0 and 1 . and the input and output of linguistics and non-linear models[11]. And in the analysis for the Uncertainty model, one of them uses Fuzzy Logic which is the foundation that provides high capabilities of final computing with coordinated distribution of resources and ensures the delivery of computing resources as expected. And performance can be judged from various criteria that must be considered simultaneously in the scheduling process, and arithmetic expressions allow mapping of assigned inputs to outputs [12].

\section{Literature Review}

For the case of Artificial Neural Networks with many and uncertain variables that cannot be solved yet which has limited generalization capabilities with binary It takes an artificial neural network model that can determine how to optimize system learning in recognizing a pattern during the process and the selection algorithm can be a solution [13]. Varied and linguistic inputs are important to solve in neural networks by grouping them in real time [14](David Zhang and Sankar K. Pal, 2016). If the system is online-based which requires very real time, the neural network model is difficult to implement [15](Shalaginov Andrii et al, 2016). Neural networks have the ability to effectively model non-linear systems by mapping between inputs and outputs [16](Jagdish Chandra Patra, 2016). And with this selection algorithm approach, it can be used to optimize the weights and parameters of the neural network that replaces imitation[17] (Stephen Ashmore and Michael Gashler, 2016). Furthermore, the output of the association unit in a simple perceptron is a binary vector. The vector is required as an input signal to the output unit in each part that follows it (Manuel Fernández et.al, 2011).

Permitted wind lashing processes and the length of power generation, high capital costs of investment and network instability due to the intermittent nature of wind, are also significant obstacles in the development of wind energy production.[3]. Twin angle windmill experiment conducted in the United States, very large in size because it was designed by Palmer Putman, 1.25 MW capacity built by the Morgen Smith Company of York Pensylvania [4]. The barometric gradient is the difference in air pressure between two isobars at any straight distance of 15 meridians or $111 \mathrm{~km}$. The power of the wind blowing in the turbine is directly proportional to its barometric gradient The greater the barometric gradient, the stronger the wind is blowing. [5] The development of wind turbines has made significant progress since the late 1960s. Several studies were conducted at home and abroad to make wind turbines with a diameter of $2 \mathrm{~cm}$ and an outer diameter of $3.2 \mathrm{~cm}[6]$. 


\section{Methods}

The data taken for analysis are the average air pressure, wind speed and solar radiation by month in the city of Medan 2015, as shown in table 1 , below

Table 1 the average air pressure, wind speed and solar radiation

\begin{tabular}{cccc}
\hline Month & Air pressure (milibar/mb) & Duration of sunshine $(\%)$ & $\begin{array}{c}\text { Target } \\
\text { Wind speed (knot) }\end{array}$ \\
\hline January & 1010,9 & 39 & 2,6 \\
Pebruary & 1010,9 & 51 & 2,6 \\
March & 1010,6 & 51 & 2,6 \\
April & 1010,8 & 32 & 2,5 \\
May & 1010,5 & 37 & 2,2 \\
June & 1010,5 & 47 & 2,4 \\
July & 1010,5 & 37 & 2,2 \\
Agust & 1010,4 & 42 & 2,5 \\
September & 1010,6 & 34 & 2,4 \\
October & 1010,3 & 39 & 1,9 \\
November & 1010,1 & 37 & 2,0 \\
December & 1010,3 & 41 & 2,2 \\
\hline
\end{tabular}

Source: Climatology Station to Medan/ https://medankota.bps.go.id /

The research variable is a symbol, characteristic or level of an entity or activity that has a special variety that is used by researchers to study and draw a conclusion [18]. And the variables in this study consisted of independent variables and 1 dependent variable. The dependent variable is air velocity. The independent variables are air pressure and water irradiation. Data on wind speed and wind direction in Belawan and surrounding areas in 2012, according to the table above.

The model used is the Artificial Neural Network model for Uncertain Variables with the following algorithm[19] [20]

1. Forming the input matrix

2. Establish membership degrees derajat

3. Selection with logical OR (max value) from each criterion.

4. Forming the input by expressing it as a row vector

5. Forming variable preference weights based on output using the Probability technique

6. Determine the Minimum Output value with Linear Programming techniques.

7. Selecting several variables based on the relationship between variables and output

8. Selecting the input data by calculating the Euclidean distance between each row vector to represent the input.

9. Conduct training

10. Doing the test

\section{Results and Discussion}

\subsection{Data}

Wind potential that can be utilized for wind energy generation is wind potential with a minimum speed of $4.16 \mathrm{~m} / \mathrm{s}$. And specifically for the country of Indonesia, the total load capacity of electric generators sourced from wind power with an average speed of approximately $2.5 \mathrm{~m} / \mathrm{s}$ and equal to $9 \mathrm{~km} / \mathrm{hour}$ or $5.0 \mathrm{knots} /$ hour is suitable for devices that cause energy with a low proportion especially in coastal areas. , mountains and free areas. Wind potential that can be utilized for wind energy generation is wind potential with a minimum speed of $4.16 \mathrm{~m} / \mathrm{s}$. And specifically for the country of Indonesia, the proportion of the number of electric generators sourced from air power with an average air speed of approximately $2.5 \mathrm{~m} / \mathrm{s}$ equals $9 \mathrm{~km} / \mathrm{hour}$ or $5.0 \mathrm{knots} /$ hour according to low priority generators in coastal, mountainous areas mountains and free areas. From this explanation, it is a picture of the potential for the windmill to rotate or not. The first step of this analysis is to form an input matrix for the average air pressure and solar irradiance as shown in Table 2. potential of rotating windmill.

Table 2. Input matrix for average air pressure and solar irradiance

\begin{tabular}{lll}
\hline 1010,9 & 39 & 2,6 (potential of rotating windmill) \\
1010,9 & 51 & 2,6 (potential of rotating windmill) \\
1010,6 & 51 & 2,6 (potential of rotating windmill) \\
1010,8 & 32 & 2,5 (potential of rotating windmill) \\
1010,5 & 37 & 2,2 (potential of not rotating windmill) \\
1010,5 & 47 & 2,4 (potential of not rotating windmill) \\
1010,5 & 37 & $2,2($ potential of not rotating windmill) \\
1010,4 & 42 & $2,5($ potential of rotating windmill) \\
1010,6 & 34 & 2,4 (potential of not rotating windmill) \\
1010,3 & 39 & 1,9 (potential of not rotating windmill) \\
1010,1 & 37 & 2,0 (potential of not rotating windmill) \\
1010,3 & 41 & 2,2 (potential of not rotating windmill) \\
\hline
\end{tabular}




\subsection{Membership Function}

The membership function is a curve that shows the mapping of data input points into the membership value or membership degree which has an interval between 0 to 1 . And the data is described or represented by a curve. In this study, each data is indicated by its membership function, both the average air pressure, wind speed and solar radiation, which are represented on a trapezoidal curve. For the air-affected variable (millibar/mb) it is represented by its membership function as shown in Figure 1 .

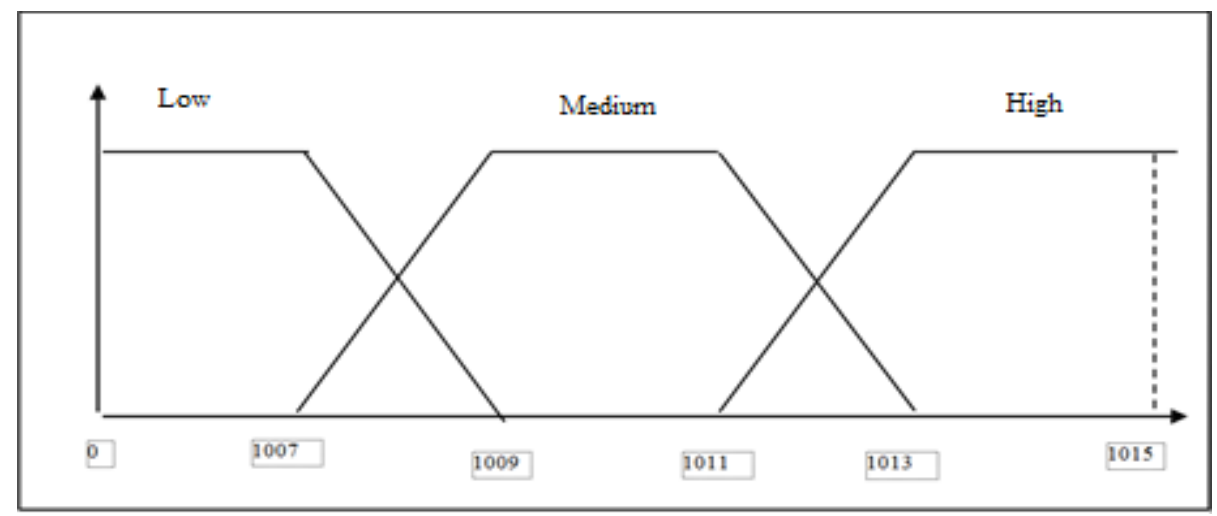

Fig 1. Degree of membership of air pressure (millibar/mb)

The value of the degree of membership of the air pressure [21]

$$
0 ; \mathrm{x} \geq 1009
$$

$\mu$ low $[x]=(1009-x) /(1009-1007), 1007 \leq x \leq 1009 ; \mu$ high $[x]=(x-1011) /(1013-1011) ; 1013 \leq x \leq 1011$

$$
1 ; \mathrm{x} \leq 1007
$$$$
1 ; \mathrm{x} \geq 1013
$$

$0 ; \mathrm{x} \leq 1007$ or $\mathrm{x} \geq 1013$

$\mu$ medium $[\mathrm{x}]=(\mathrm{x}-1007) /(1009-1007) ; 1007 \leq \mathrm{x} \leq 1009$

$1 ; 1007 \leq \mathrm{x} \leq 1009$

$(1013-\mathrm{x}) /(1013-1011) ; 1011 \leq \mathrm{x} \leq 1013$

The membership function of solar irradiance $(\%)$ with a curve that shows the mapping of input points of solar irradiance data into membership degrees that have an interval between 0 to 1 . And this solar irradiance data is represented by a trapezoidal curve. For the solar irradiation variable (\%) with Low, Medium and High criteria which have intervals of 0 and 1 , it is represented by the membership function as shown in Figure 2, below.

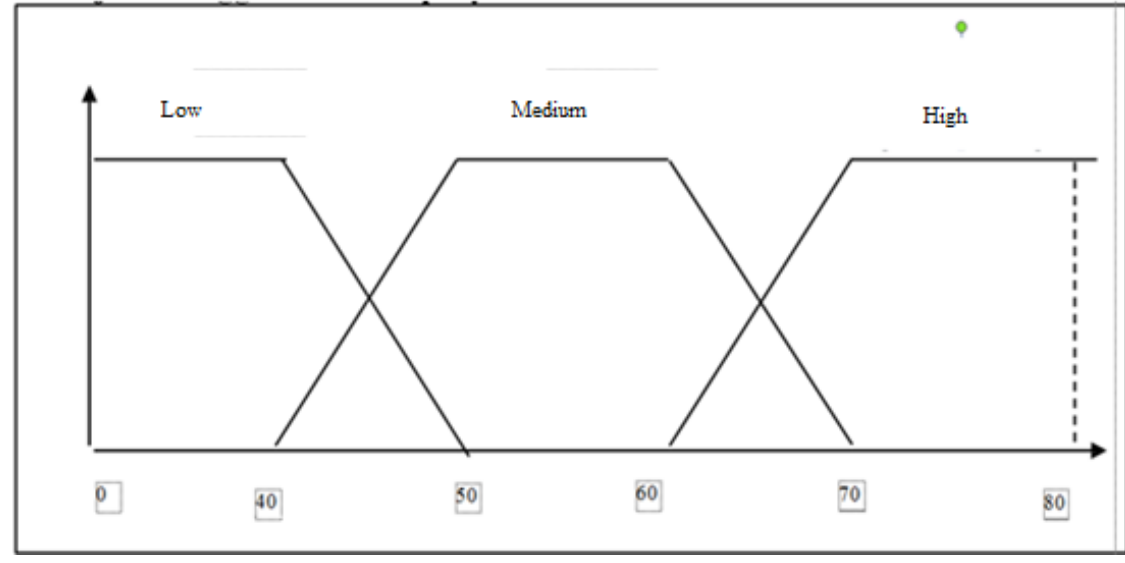

Fig 2. Degree of Membership from sunlight (\%)

The value of the membership degree of solar irradiation [22] :

$$
0 ; \mathrm{x} \geq 50
$$$$
0 ; \leq 60
$$

$\mu_{\text {Low }}[\mathrm{x}]=(50-\mathrm{x}) /(50-40), 40 \leq \mathrm{x} \leq 50 ; \mu_{\text {High }}[\mathrm{x}]=(\mathrm{x}-60) /(70-60) ; 60 \leq \mathrm{x} \leq 70$

$$
1 ; \mathrm{x} \leq 40 \quad 1 ; \mathrm{x} \geq 60
$$

$0 ; \mathrm{x} \leq 40 \quad \mathrm{x} \geq 70 \mathrm{r}$

$\mu_{\text {Medium }}[\mathrm{x}]=(\mathrm{x}-40) /(50-40) ; 40 \leq \mathrm{x} \leq 50$

$1 ; 50 \leq \mathrm{x} \leq 60$

$(70-x) /(70-60) ; 60 \leq x \leq 70$; 


\subsection{Conversion Data}

The membership function of each data from Air Pressure and Solar Radiation using the criteria of Low, Medium and High is converted with values that have an interval between 0 to 1 . Table.3.

Table 3. Data Conversion Results

\begin{tabular}{|c|c|c|c|c|c|c|}
\hline \multirow{2}{*}{ No. } & \multicolumn{3}{|c|}{ Air pressure (milibar/mb) } & \multicolumn{3}{|c|}{ Sunshine (\%) } \\
\hline & Low & Medium & High & Low & Medium & High \\
\hline 1 & 0 & 0 & 1 & 1 & 0 & 0 \\
\hline 2 & 0 & 0 & 1 & 0 & 1 & 0 \\
\hline 3 & 0 & 0 & 1 & 0 & 1 & 0 \\
\hline 4 & 0 & 0 & 1 & 1 & 0 & 0 \\
\hline 5 & 0 & 0 & 1 & 1 & 0 & 0 \\
\hline 6 & 0 & 0 & 1 & 0,7 & 0.3 & 0 \\
\hline 7 & 0 & 0 & 1 & 1 & 0 & 0 \\
\hline 8 & 0 & 0 & 1 & 0,8 & 0,2 & 0 \\
\hline 9 & 0 & 0 & 1 & 1 & 0 & 0 \\
\hline 10 & 0 & 0 & 1 & 1 & 0 & 0 \\
\hline 11 & 0 & 0 & 1 & 1 & 0 & 0 \\
\hline 12 & 0 & 0 & 1 & 0.9 & 0.1 & 0 \\
\hline
\end{tabular}

Furthermore, the data from the conversion results of the air pressure and solar irradiation variables in Table 3 are analyzed with the next step, namely by selecting using the OR logic function (Max value) on the criteria, low, medium and high. And the data from the selection of air pressure and solar radiation variables using the OR logic function can be seen in Table 4.

Table 4. Data selection results with OR logic.

\begin{tabular}{c|c|c}
\hline No. & $\begin{array}{c}\text { Air pressure } \\
\text { (milibar/mb) }\end{array}$ & Sunshine $\left(^{\%}\right)$ \\
\hline 1 & 1 & 1 \\
2 & 1 & 1 \\
3 & 1 & 1 \\
4 & 1 & 1 \\
5 & 1 & 1 \\
6 & 1 & 0,7 \\
7 & 1 & 1 \\
8 & 1 & 0,8 \\
9 & 1 & 1 \\
10 & 1 & 1 \\
11 & 1 & 1 \\
12 & 1 & 0.9 \\
\hline
\end{tabular}

\subsection{Probability Engineering}

Establishing variable preference weights based on output with the Probability technique. Where, some explanation as following: $\mathrm{P}($ wind mill. speed $\mid$ air pressure $)=$ The probability of the wind mill speed hypothesis occurring if the evidence of pressure $\mathrm{P}($ wind mill speed $\mid$ air pressure $)=$ the probability of the wind mill speed hypothesis occurring if the evidence of air pressure occurs. $\mathrm{P}($ air pressure $\mid$ wind mill. speed $)=$ probability of the emergence of evidence of air pressure, if the hypothesis is kec. pinwheel wind occurs.

$\mathrm{P}($ wind mill speed $)=$ Hypothetical probability of windmill speed regardless of evidence .

$\mathrm{P}($ air pressure $)=$ probability evidence of air pressure regardless of anything.

$\mathrm{P}($ air pressure $\mid$ wind mill speed $)=0,6, \mathrm{P}(\mathrm{Kec} . \mathrm{KA})=0,125, P(\mathrm{TU})=0,125$,

$\mathrm{P}($ wind mill speed $\mid$ air pressure $)=(0,6.0,125) / 0,125=60 \%$

$\mathrm{P}($ temperature $\mid$ wind mill speed $)=0,4, \mathrm{P}(\mathrm{Kec} . \mathrm{KA})=0,125, \mathrm{P}($ temperatue $)=0,125$.

$\mathrm{P}($ wind mill speed $\mid$ temperature $)=(0,4.0,125) / 0,125=40 \%$

So that the weight of each variable on water quality, namely:

Air pressure $=0.6$, temperature $=0.4$, and data from each variable with a target. $\mathrm{Y}=(0,6 \mathrm{X} 1+0,4 \mathrm{X} 2)$. 


\subsection{Determining weights and targets}

Data 1: $\mathrm{x}_{1}=1 . \mathrm{x}_{2}=1, \mathrm{Y}=(0,6 \mathrm{x} 1+0,4 \mathrm{x} 2), \mathrm{Y}=1, \mathrm{Y} \geq 1$, so the rotation of wind mill moving

Data 2: $\mathrm{x}_{1}=1 . \mathrm{x}_{2}=1, \mathrm{Y}=1, \mathrm{Y} \geq 1$ so the rotation of wind mill moving

Data 3: $x_{1}=1 . x_{2}=1, Y=1$, so the rotation of wind mill moving

Data 4: $\mathrm{x}_{1}=1 . \mathrm{x}_{2}=1, \mathrm{Y}=1$, so the rotation of wind mill moving

Data 5: $\mathrm{x}_{1}=1 . \mathrm{x}_{2}=1, \mathrm{Y}=1$, so the rotation of wind mill moving

Data 6: $\mathrm{x}_{1}=1 . \mathrm{x}_{2}=0.7, \mathrm{Y}=0.88, \mathrm{Y} \leq 1$, so the rotation of wind mill not moving

Data 7: $\mathrm{x}_{1}=1 . \mathrm{x}_{2}=1, \mathrm{Y}=1$, so the rotation of wind mill not moving

Data 8: $\mathrm{x}_{1}=1 . \mathrm{x}_{2}=0.8, \mathrm{Y}=0.92, \mathrm{Y} \leq 1$, so the rotation of wind mill not moving

Data 9: $\mathrm{x}_{1}=1 . \mathrm{x}_{2}=1, \mathrm{Y}=1$, so the rotation of wind mill moving

Data 10: $\mathrm{x}_{1}=1 . \mathrm{x}_{2}=1, \mathrm{Y}=1$, so the rotation of wind mill moving

Data 11: $\mathrm{x}_{1}=1 . \mathrm{x}_{2}=1 . \mathrm{Y}=1$, so the rotation of wind mill moving

Data 12: $\mathrm{x}_{1}=1 . \mathrm{x}_{2}=0.9, \mathrm{Y}=0.96$, so the rotation of wind mill not moving

\subsection{Data Selection with Euclidean distance}

The less air pressure, the greater of wind speed. And the greater of sunlight, the greater of wind speed.

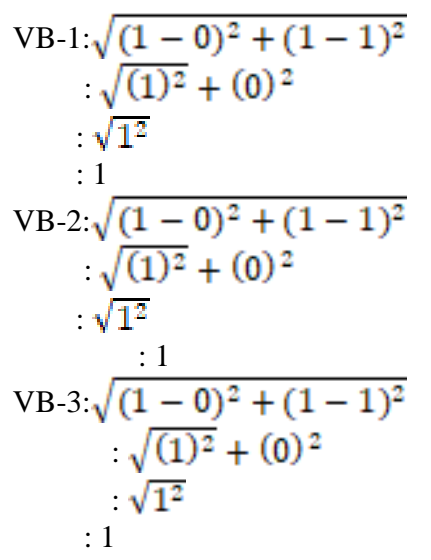

VB-4 :1, VB-5 :1, VB-6 :0,88, VB-7 : 1, VB-8 : 0,92, VB-9 : 1, VB-10 : 1, VB-11 :1, VB-12:0,96

The ranking data for each vector, namely VB-1 to VB-12 is the result of selection by calculating the Euclidean distance of each vector. And the results of the ranking data for each row vector can be seen in Table 5.

Table 5. Ranking data for each row vector

\begin{tabular}{cccc}
\hline No & Row Vector & $\begin{array}{c}\text { Nearest Euclidean Dis- } \\
\text { tance }\end{array}$ & Rank \\
\hline $\mathbf{1}$ & & 0,88 & 1 \\
$\mathbf{2}$ & 6 & 0,92 & 2 \\
$\mathbf{3}$ & 12 & 0,96 & 3 \\
$\mathbf{4}$ & 1 & 1 & 4 \\
$\mathbf{5}$ & 2 & 1 & 5 \\
$\mathbf{6}$ & 3 & 1 & 6 \\
$\mathbf{7}$ & 4 & 1 & 7 \\
$\mathbf{8}$ & 5 & 1 & 8 \\
$\mathbf{9}$ & 7 & 1 & 9 \\
$\mathbf{1 0}$ & 9 & 1 & 10 \\
$\mathbf{1 1}$ & 10 & 0,377 & 11 \\
$\mathbf{1 2}$ & 11 & 0.377 & 12 \\
\hline
\end{tabular}

The data for the highest ranking of row vectors can be seen in Table 6 below.

Table 6. The highest ranking of the 12 inputs

\begin{tabular}{lcccc}
\hline No & RV & Nearest Euclidean Distance & Rank & \multicolumn{1}{c}{ Target } \\
1 & 6 & 0,88 & 1 & $\begin{array}{l}\text { the rotation of wind mill } \\
\text { moving/ } 0\end{array}$ \\
2 & 8 & 0,92 & 2 & $\begin{array}{l}\text { the rotation of wind mill } \\
\text { moving/ 0 } \\
\text { the rotation of wind mill } \\
\text { moving/0 } \\
\text { the rotation of wind mill } \\
\text { not moving/ 1 }\end{array}$ \\
\hline
\end{tabular}


4.7 Training of selected data

Starting with data training starting from data 1 to data 12 .

\section{Epoch 1}

Rangk ( Data 1 / RV-6)

$\mathrm{x}_{1}=1, \mathrm{x}_{2}=0,7, \mathrm{w}_{1}=0, \mathrm{w}_{2}=0$, bias $=0, \theta=0,6, \alpha=0,2, \mathrm{~T}=0$ $\mathrm{y}$-in $=$ bias+ $(\mathrm{x} 1 . \mathrm{w} 1+\mathrm{x} 2 . \mathrm{w} 2)$

$$
\begin{aligned}
& =0,1+(1.0+0,7.0) \\
& =0,1
\end{aligned}
$$

Put in the activation function:

$f(x)=\mathrm{Y}=\left\{\begin{array}{l}1_{\text {, if }} y_{\text {-in }}>\theta \\ 0, \text { if }-\theta \leq y_{\operatorname{lin}} \leq \theta \\ -1_{\text {, if } y} y<\theta\end{array}\right.$

$\mathrm{f}(\mathrm{x})=\mathrm{Y}=\left\{\begin{array}{l}1_{\text {, if }} y_{\text {-in }}>0,6 \\ 0, \text { if }-0,6 \leq y_{\text {-in }} \leq 0,6 \\ -1_{\text {, if }} y \text { in }<0,6\end{array}\right.$

$\mathrm{Y}=0=\mathrm{T}$ (no change in weight and bias).

\section{Rangk (Data 2 / RV-8)}

$\mathrm{x}_{1}=1, \mathrm{x}_{2}=0,8, \mathrm{w}_{1}=0, \mathrm{w}_{2}=0$, bias $=0, \theta=0,6, \alpha=0,2, \mathrm{~T}=0$ $\mathrm{y}$-in $=$ bias+ $(\mathrm{x} 1 . \mathrm{w} 1+\mathrm{x} 2 . \mathrm{w} 2)$

$=0,1+(1.0+0,8.0)$

$=0,1$

Put in the activation function:

$$
\mathrm{f}(\mathrm{x})=\mathrm{Y}=\left\{\begin{array}{c}
1, \text { if } y_{-i n}>0,6 \\
0, \text { if }-0,6 \leq y_{\text {-in }} \leq 0,6 \\
-1, \text { if } y_{\text {in }}<0,6
\end{array}\right.
$$

$\mathrm{Y}=0=\mathrm{T}$ (no change in weight and bias).

\section{Rank (Data 3 / RV-12)}

$\mathrm{x}_{1}=1, \mathrm{x}_{2}=0,9, \mathrm{w}_{1}=0, \mathrm{w}_{2}=0$, bias $=0, \theta=0,6, \alpha=0,2, \mathrm{~T}=0$

$\mathrm{y}$-in $=$ bias+ $(\mathrm{x} 1 . \mathrm{w} 1+\mathrm{x} 2 . \mathrm{w} 2)$

$=0,1+(1 \cdot 0+0,9.0)$

$=0,1$.

Put in the activation function:

$$
\mathrm{f}(\mathrm{x})=\mathrm{Y}=\left\{\begin{aligned}
1_{x} \text { if } y_{\text {-in }} & >0,6 \\
0, \text { if }-0,6 & \leq y_{\text {-in }} \leq 0,6 \\
-1, \text { if } y \text { in } & <-0,6
\end{aligned}\right.
$$

$\mathrm{Y}=0=\mathrm{T}$ (no change in weight and bias).

\section{Rank (Data 4 (RV-1)}

$\mathrm{x}_{1}=1, \mathrm{x}_{2}=1, \mathrm{w}_{1}=0, \mathrm{w}_{2}=0$, bias $=0, \theta=0,6, \alpha=0,2, \mathrm{~T}=1$

$\mathrm{y}$-in $=$ bias $+(\mathrm{x} 1 . \mathrm{w} 1+\mathrm{x} 2 . \mathrm{w} 2)$

$$
=0,1+(1.0+1.0)
$$

$=0,1$.

Put in the activation function:

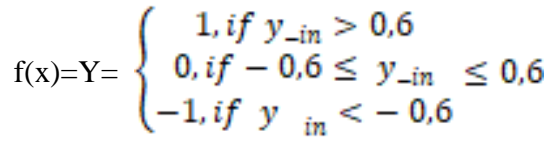

$\mathrm{Y}=0 \neq \mathrm{T}$ (change in weight and bias)

$$
\begin{aligned}
\mathrm{w}_{1}(\text { new }) & =\mathrm{w}_{1}(\text { old })+\alpha \cdot t \cdot \mathrm{x}_{1} \\
& =0+0,2 \cdot 1 \cdot 1 \\
& =0,2 \\
\mathrm{w}_{2}(\text { new }) & =\mathrm{w}_{2}(\text { old })+\alpha . t . \mathrm{x}_{2} \\
& =0+0,2 \cdot 1 \cdot 1 \\
& =0,2 \\
\text { bias (new) } & =\text { bias }(\text { old })+\alpha . \mathrm{t} \\
& =0+0,2.1 \\
& =0,2, \text { so } \mathrm{w}_{1}=0,2, \mathrm{w}_{2}=0,2,
\end{aligned}
$$




\section{Epoch 2}

\section{Rank (Data 1 / RV-6)}

$\mathrm{x} 1=1, \mathrm{x} 2=0,7, \mathrm{w} 1=0,2, \mathrm{w} 2=0,2$, bias $=0,2, \theta=0,6, \alpha=0,2, \mathrm{~T}=0$

$\mathrm{y}$-in $=$ bias $+(\mathrm{x} 1 . \mathrm{w} 1+\mathrm{x} 2 . \mathrm{w} 2)$

$=0,2+(1.0,2+0,7.0,2)=$

$=0,54$

$\mathrm{Y}=0=\mathrm{T}$ (no change in weight and bias).

\section{Rank (Data 2 / VB-8)}

$\mathrm{x} 1=1, \mathrm{x} 2=0,8, \mathrm{w} 1=0,4, \mathrm{w} 2=0,2$, bias $=0,2, \theta=0,6, \alpha=0,2, \mathrm{~T}=0$

$\mathrm{y}$-in $=$ bias+ $(\mathrm{x} 1 . \mathrm{w} 1+\mathrm{x} 2 . \mathrm{w} 2)$

$=0,2+(1 \cdot 0,2+0,8 \cdot 0,2)$

$=0,56$

$\mathrm{Y}=0=\mathrm{T}$ (no change in weight and bias).

\section{Rank (Data 3 /VB-12)}

$\mathrm{x} 1=1, \mathrm{x} 2=0,9, \mathrm{w} 1=0,4, \mathrm{w} 2=0,2$, bias $=0,2, \theta=0,6, \alpha=0,2, \mathrm{~T}=0$

$\mathrm{y}$-in $=$ bias $+(\mathrm{x} 1 . \mathrm{w} 1+\mathrm{x} 2 . \mathrm{w} 2)$

$=0,2+(1 \cdot 0,2+0,9 \cdot 0,2)=$

$=0,58$

$\mathrm{Y}=0=\mathrm{T}$ (no change in weight and bias).

Rank (Data 3 / VB-1)

$\mathrm{Y}=1=\mathrm{T}$ (no change in weight and bias).

$\mathrm{x} 1=1, \mathrm{x} 2=1, \mathrm{w} 1=0,4, \mathrm{w} 2=0,2, \mathrm{bias}=0,2, \theta=0,6, \alpha=0,2, \mathrm{~T}=1$

$\mathrm{y}$-in $=$ bias+ $(\mathrm{x} 1 . \mathrm{w} 1+\mathrm{x} 2 . \mathrm{w} 2)$

$=0,2+(1.0,2+1.0,2)$

$=0.2$

\subsection{Data Testing}

Data testing is an attempt to analyze data as confirmation, to verify that a set of inputs given to a particular function produces some expected results. And the test is carried out after the training on input data starting from data 1 to data 12 . And in the analysis of this research the data tested is data 11 , after obtaining the weight and bias values from the training results according to Table 7 , below.

Table 7. Data Testing

\begin{tabular}{ccc}
\hline No & $\mathbf{X}_{\mathbf{1}}$ & $\mathbf{X}_{\mathbf{2}}$ \\
\hline 11 & 1 & 1 \\
\hline
\end{tabular}

$\mathrm{x} 1=1, \mathrm{x} 2=1, \mathrm{w} 1=0,4, \mathrm{w} 2=0,2$, bias $=0,2, \theta=0,6, \alpha=0,2, \mathrm{~T}=1$

$\mathrm{y}$-in $=$ bias+ $(\mathrm{x} 1 . \mathrm{w} 1+\mathrm{x} 2 . \mathrm{w} 2)$

$=0,2+(1.0,2+1.0,2)$

$$
=0,6
$$

Put in the activation function:

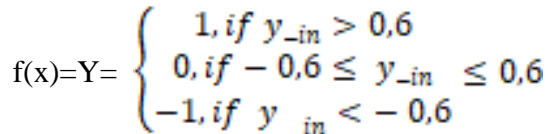

$\mathrm{Y}=1$ (the rotation of wind mill moving)

\section{Conclusion}

The use of wind mill plays a role in producing wind power which can be used as a source of electrical energy. The movement of this wind mill is a matter of uncertainty, to determine whether or not the wind mill moves. So that the model used in this study is the Artificial Neural Network model for Uncertain Variables (VTP) which is a selection model using probability techniques, membership degrees, logical OR functions, linear programming and Euclidean distance to reduce the learning process. The Artificial Neural Network Model for Uncertain Variables (VTP) is implemented on a wind mill with variable air pressure and solar radiation. And with training carried out on the system and further testing is carried out, it can determine whether the wind mill is moving or the wind mill is not moving. And with the Artificial Neural Network model for Uncertain Variables, Wind mill control can be used with different input data with air pressure and water irradiation variables. And it is hoped that in the next research it can be done with more variables and determine windmill speed. And with the Artificial Neural Network model for Uncertain Variables, it can be used to control Wind mills with different input data.

\section{References}

[1] V. L. Narayanan and R. Ramakrishnan, "Pitch Control of a Digital Hydraulics Pitch System for Wind Turbine Based on NeuroFuzzy Digital Pitch Controller," Int. J. Renew. Energy Res., vol. 11, no. 1, pp. 417-425, 2021.

[2] M. Lauranti and E. A. Djamhari, "Transisi Energi yang Setara di Indonesia: Tantangan dan Peluang," vol. (C) 2017 Fri, no., p. 48 , 2017, [Online]. Available: http://library.fes.de/pdf-files/bueros/indonesien/14758.pdf. 
[3] E. I. Konstantinidis and P. N. Botsaris, "Wind turbines: Current status, obstacles, trends and technologies," IOP Conf. Ser. Mater. Sci. Eng., vol. 161, no. 1, 2016, doi: 10.1088/1757-899X/161/1/012079.

[4] J.Wignesh and S. C. A, "Design and fabrication of vertical axis wind mill with solar system," Mater. Today Proc., vol. 44, no., p., 2021, [Online]. Available: https://www.sciencedirect.com/science/article/pii/S2214785319311526.

[5] S. Widyanto, S. Wisnugroho, and M. Agus, "Pemanfaatan Tenaga Angin Sebagai Pelapis Energi Surya pada Pembangkit Listrik Tenaga Hibrid di Pulau Wangi-Wangi," Semin. Nas. Sain dan Teknol. 2018, pp. 1-12, 2018.

[6] S. Hernowo, "Rancang bangun turbin angin sumbu horizontal sederhana dengan panjang sudu 1 meter sigit hernowo," $J$. Voering, vol. $5, \quad$ no. $1, \quad$ pp. 15-21, 2020, [Online]. $\quad$ Available: http://jurnal.poltekstpaul.ac.id/index.php/jurvoe/article/view/216/145.

[7] Z. Azmi and V. Yasin, Pengantar Sistem pakar dan Metode. Mitra Media Wacana, 2017.

[8] Z. Azmi and V. Yasin, Pengantar jaringan saraf tiruan (introduction to artificial neural network). Mitra Media Wacana, 2021.

[9] Z. Azmi and H. Mawengkang, "Perceptron Genetic to Recognize Openning Strategy Ruy Lopez," IOP Conf. Ser. Mater. Sci. Eng., vol. 300, no. 1, 2018, doi: 10.1088/1757-899X/300/1/012069.

[10] H. Kukreja, "An introduction to artificial neural networks," Hardw. Archit. Deep Learn., no. 5, pp. 3-26, 2020, doi: 10.1049/pbcs055e_ch1.

[11] Z. Azmi, E. B. N. BN, H. Mawengkang, and M. ZARLIS, "Neuron Model for Input Uncertainty," J. Telemat. dan Informatics, vol. 6, no., pp. 166-172, 2018, doi: 10.12928/jti.v6i2.

[12] Z.- Azmi, M. K. M. Nasution, H. Mawengkang, and M. Zarlis, "Uncertainty Ontology for Module Rules Formation Waterwheel Control," Sci. J. Informatics, vol. 5, no. 1, p. 66, 2018, doi: 10.15294/sji.v5i1.14188.

[13] JJ. De Groote and D.M.L. Barbato, "Generalization of finite size Boolean perceptrons with genetic algorithms.," Neurocomputing, vol. 71, no. 16-18, October 2008, pp. 3650-3655, 2008.

[14] D. Z. and S. K. Pal, "A fuzzy clustering neural networks (FCNs) system design methodology,” Natl. Libr. Med., vol. 11, no. 5, Sept. 2000, pp. 1174-1177, 2016.

[15] S. Andrii, "Multinomial classification of web attacks using improved fuzzy rules learning by Neuro-Fuzzy.," Int. J. Hybrid Intell. Syst. V, vol. 13, no., pp. 15-26, 2016.

[16] J. C. Patra, "Chebyshev neural network-based model for dual-junction solar cells," IEEE Trans. Energy Convers., vol. 26, no. 1, pp. 132-139, 2011, doi: 10.1109/TEC.2010.2079935.

[17] S. Ashmore and M. Gashler, "A method for finding similarity between multi-layer perceptrons by Forward Bipartite Alignment," Proc. Int. Jt. Conf. Neural Networks, vol. 2015-Septe, 2015, doi: 10.1109/IJCNN.2015.7280769.

[18] Sugiyono, Metode penelitian pendidikan:(pendekatan kuantitatif, kualitatif dan $R \& D$ ). Bandung CV. Alfabeta: CV. Alfabeta, 2008 .

[19] Z. AZMI, "MODEL JARINGAN SARAF TIRUAN UNTUK VARIABEL TIDAK PASTI,” Medan, 2020. [Online]. Available: http://repositori.usu.ac.id/handle/123456789/28542.

[20] Z. AZMI, M. ZARLIS, and H. MAWENGKANG, "UNCERTAIN INPUT SELECTION MODEL FOR NEURON," JATIT, vol. 97, no. 21, p. 2982, 2019, [Online]. Available: JURNAL SUBMIT UNTUK LEKTOR KEPALA/MODEL JARINGAN SARAF TIRUAN.pdf.

[21] H. P Dida, S. Suparman, and D. Widhiyanuriyawan, "Pemetaan Potensi Energi Angin di Perairan Indonesia Berdasarkan Data Satelit QuikScat dan WindSat," J. Rekayasa Mesin, vol. 7, no. 2, pp. 95-101, 2016, doi: 10.21776/ub.jrm.2016.007.02.7.

[22] A. \& H. Pujiastuti, "Sistem Perhitungan Lama Penyinaran Matahari ( Studi Kasus : ST . KLIMATOLOGI BARONGAN )," Jur. Ilmu Komputer, FMIPA UGM, vol. 5, 2016, [Online]. Available: http://ejournals.stta.ac.id/index.php/compiler/article/view/166. 